\title{
Decisão informada
}

António Faria Vaz*

\section{O fármaco é um marcador universal do fazer} e do saber (ou do não saber médico).

G. Tognoni ${ }^{1}$

Clearly, it is more difficult not to prescribe than to prescribe. Medicines are generally viewed as good, and prescribing as beneficent act

David Lowental e George Caranasos ${ }^{2}$

$\mathrm{E}$ $\mathrm{m}$ Portugal, $61,5 \%$ das receitas de medicamentos são prescritas por médicos de família, $18,7 \%$ por médicos do sector privado e os restantes $12,7 \%$ por médicos hospitalares. ${ }^{3}$ Sendo a receita médica um indicador indirecto, e o único a abranger todos os tipos de prestadores médicos de cuidados de saúde, pode, através destes números, afirmar-se a importância que a Medicina Geral e Familiar tem no contexto da prestação de cuidados de saúde em Portugal e o papel determinante que a nossa especialidade tem no consumo de medicamentos no país.

Este aspecto releva o papel crucial que a Medicina Geral e Familiar tem para a sustentabilidade do Serviço Nacional de Saúde, sendo mesmo um factor essencial a qualquer política que procure optimizar a utilização de recursos e promover a qualidade dos cuidados de saúde, garantindo a equidade no seu acesso.

$\mathrm{O}$ uso racional de um medicamento implica uma abordagem individual, centrada no doente. O sucesso de uma determinada terapêutica farmacológica depende da habilidade do médico para diagnosticar um problema de saúde, da selecção do medicamento, da dosagem e via de administração apropriadas, da capacidade de antever as reacções adversas e interacções medicamentosas potenciais e de prevenir duplicações terapêuticas desnecessárias. É este o modelo tradicional que se baseia na precisão diagnóstica, no conhecimento e no saber farmacológico e terapêutico de um clínico, condição necessária e suficiente de garantia da eficácia e segurança dos medicamentos. ${ }^{1}$

*Director da Revista Portuguesa de Clínica Geral
Sabemos, no entanto, que os factores que determinam a prescrição não estão apenas relacionados com factores biomédicos, pois muitos outros a influenciam. As características dos médicos, ${ }^{4}$ a duração da consulta, as características dos doentes e as suas expectativas relativamente aos medicamentos, ${ }^{5}$ os amigos e familiares do doente, a indústria farmacêutica, ${ }^{6}$ os colegas ${ }^{7}$ e as próprias autoridades de Saúde. ${ }^{8}$

Realce-se que num estudo recente com médicos de família no Reino Unido, relativo aos factores que determinam o conhecimento de um novo fármaco, o delegado de informação médica surge como o elemento mais destacado, logo seguido das revistas sem revisão interpares e dos órgãos de comunicação social gerais. Com menor expressão, surgem os colegas de outras especialidades hospitalares. ${ }^{9}$ Estes dados são muito semelhantes aos do estudo do INFARMED em que os médicos de família consideravam as revistas, os delegados de informação médica e os livros e tratados, como as fontes de informação mais importantes sobre medicamentos..$^{10}$ Interessante, no estudo que anteriormente referimos, o facto de os autores considerarem que o factor determinante na decisão de prescrever um novo medicamento não se baseia em critérios biomédicos e/ou farmacológicos, mas na forma e na via como se faz a transferência da informação e, em particular, as influências sociais e interpessoais que são decisivas na forma como os médicos de família avaliam a evidência e a integram na prática clínica. E, finalmente, que o sucesso dessa comunicação depende da facilidade do acesso à informação (os delegados de informação são considerados o meio mais acessível e disponível de aceder à informação e de se manter actualizado); da credibilidade do comunicador (neste capítulo os médicos de outras especialidades foram considerados como um dos elementos mais influentes) e da sua própria experiência clínica (a «experimentação clínica» - se a expectativa inicial for positiva, reforça as expectativas e pode determinar a prescrição futura) ${ }^{9}$

É certamente importante que se analisem os determinantes e as variáveis da selecção de medicamentos, para fundamentar as estratégias conducentes a ganhos em saúde. 
Ora, aqui reside uma das maiores deficiências no nosso Sistema de Saúde, pois não é usual estudar, em termos de ganhos em saúde, os resultados das decisões sobre a adopção de novas tecnologias, onde se incluem, naturalmente, os medicamentos e outras tecnologias. Neste particular, dispomos de uma janela de oportunidade que nos é dada pela adopção de sistemas de informação clínicos electrónicos, permitindo e possibilitando a determinação do valor acrescentado das tecnologias de saúde e o seu contributo para a obtenção de ganhos, para o cumprimento da missão e da própria sobrevivência do Serviço Nacional de Saúde. ${ }^{11}$ Para tal, interessaria promover a criação de condições para que, de uma forma sistemática e organizada, se proceda à análise dos dados do sistema de informação em saúde, quer pela criação de departamentos de epidemiologia e de estatística nas administrações regionais de saúde e nos hospitais, quer pela definição de programas de apoio à investigação em serviços de saúde em articulação com as Universidades Portuguesas com competência demonstrada nesta área. Uma tal decisão permitiria aprofundar os nossos conhecimentos sobre a saúde em Portugal e, certamente, seria um instrumento essencial para melhorarmos a eficiência e a efectividade da prestação de cuidados de saúde em Portugal.

A prescrição médica é, aliás, o tema do dossier da presente revista, que conta com a colaboração de especialistas de diversas áreas do conhecimento, que nos dão a sua visão sobre o medicamento e seus contextos, onde se inclui o marketing farmacêutico, a prescrição médica, a polifarmacoterapia e a prescrição electrónica.

Numa outra dimensão, o artigo do Prof. José Manuel Pureza e o trabalho realizado pelos internos do Ano Comum do Hospital de Santa Maria, cada um à sua maneira, apelam aos valores que devem presidir à relação médico-doente preservando a sua autonomia (a informação e o conhecimento são considerados essenciais nessa relação - $94 \%$ considera importante ou muito im- portante que o médico de família forneça toda a informação ao doente) e a sua cidadania.

Diria que, na presente revista, se evidencia a necessidade de nos processos de decisão clínica (ao nível micro ou macro) se incorporar a informação e o conhecimento que são diariamente produzidos no sistema de saúde.

Boa leitura.

\section{REFERÊNCIAS BIBLIOGRÁFICAS}

1. Tognoni G, Laporte JR. Estudios de utilización de medicamentos y de farmacovigilancia: Laporte JR, Tognoni G.. Principios de epidemiologia del medicamento. $2^{\text {a }}$ ed. Barcelona: Masson-Salvat; 1993. p. 1-23.

2. Lowenthal DT, Caranasos GJ. Pharmaceutics, issues in prescribing. In: Post SG, editor. Encyclopedia of Bioethics. 3rd ed. New York: MacMillan Reference; 2004.

3. Alves A, Batel Marques F, Rodrigues V, et al. Monitorização da Prescrição por DCl e Implementação da Receita Médica. Lisboa: Observatório do Medicamento e dos Produtos de Saúde, Infarmed; 2005.

4. Inman W, Pearce G. Prescriber profile and post-marketing surveillance. Lancet 1993 Dec 11; 342 (8885): 658-61.

5. Morgan JP, Weintraub M. Course on the social functions of prescription drugs: seminar syllabus and bibliography. Ann Intern Med 1972 Aug; 77 (2): 217-22.

6. Peay MY, Peay ER. The role of commercial sources in the adoption of a new drug. Soc Sci Med 1988; 26 (12): 1183-9.

7. Feely J, Chan R, McManus J, O'Shea B. The influence of hospital-based prescribers on prescribing in general practice. Pharmacoeconomics 1999 Aug; 16 (2): 175-81.

8. Arnau JM, Laporte JR. Promoción del uso racional de los medicamentos y preparación de guías farmacológicas In: Laporte JR, Tognoni G. Principios de epidemiologia del medicamento. $2^{\text {a }}$ ed. Barcelona, Masson-Salvat; 1993. p. 49-66..

9. Prosser $\mathrm{H}$, Almond $\mathrm{S}$, Wallet $\mathrm{T}$. Influences on GPs' decision to prescribe new drugs: the importance of who says what. Fam Pract 2003 Feb; 20 (1): 61-8.

10. António A, Remísio E, Maria V. Informação Científica sobre Medicamentos. Lisboa: Observatório do Medicamento e dos Produtos de Saúde, INFARMED; 2002.

11. Oliveira J. O que esperam dos epidemiologistas os decisores clínicos em Oncologia. VI Congresso Português de Epidemiologia: Porto, 23 e 24 de Outubro. Porto: Associação Portuguesa de Epidemiologia; 2008. 